\title{
To work or not to work: labour market participation of people with spinal cord injury living in Switzerland
}

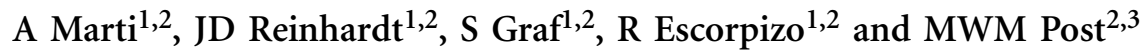

Study design: Cross-sectional survey.

Objectives: To establish labour market participation figures of persons with spinal cord injury (SCI) living in Switzerland and to investigate determinants and consequences of having paid work.

Setting: Community.

Methods: A survey among members of the Swiss Paraplegic Association was performed in 2008. Inclusion criteria were: SCl of traumatic or non-traumatic origin, minimum age of 18 years, and living in the community for at least 1 year. A total of 559 persons with $\mathrm{SCl}$ returned the questionnaire (response rate 27\%), of which 495 (24\%) fulfilled the eligibility criteria. Bivariate and logistic regression analyses were performed based on theoretical considerations and relevant determinants found in the literature.

Results: Of the respondents of working age, $63.8 \%$ were involved in gainful employment. No significant difference between persons with para- and tetraplegia was observed. Logistic regression showed that employment was associated with age, time since onset of SCI, having worked at 2 years after initial rehabilitation, having received vocational counselling, having less pain, more years of education and more perceived importance of work. Working persons achieved a significantly higher total income. The most important reasons to work were not financial, but rather of social nature. Barriers to work were primarily health-related.

Conclusions: We found a relatively high employment rate among the studied persons with SCI living in Switzerland. However, because of the low response, it is difficult to generalise this finding.

Spinal Cord (2012) 50, 521-526; doi:10.1038/sc.2011.181; published online 17 January 2012

Keywords: spinal cord injury; employment; return to work; determinants of working; consequences of working

\section{INTRODUCTION}

In Switzerland, like in many other European countries, the high unemployment rate in persons with disabilities is one of the key issues in social policy and debate. ${ }^{1}$ Improving labour market participation (LMP) of persons with disabilities is advantageous for everyone. For persons living with spinal cord injury (SCI), LMP has positive effects on many life areas such as self-realisation, selfesteem, health, better overall social integration and participation. ${ }^{2-3}$ From the employers perspective it has been shown that LMP of persons with disabilities has positive effects on the total workforce of an organisation, for example, the decreased absence and fluctuation rates. ${ }^{4}$ The society as a whole also benefits in terms of fewer disability pensions, higher tax revenue and more labour force diversity. ${ }^{3}$

The LMP in the international SCI population varies between 3 and $80 \%$, in part because of inconsistent definitions of work and inconsistent study methods. ${ }^{5}$ If solely paid work is considered, an average LMP of $35 \%$ was found across studies. ${ }^{5}$ Frequently found factors associated with LMP in SCI are gender, marital status, education, disability severity, age, time since onset of SCI, social support, vocational counselling, perceived health and pain.,3,5-9 However, the existing evidence on determinants of LMP in SCI is inconsistent. Although in some studies injury severity and gender are associated with LMP, others show the contrary. ${ }^{2,10}$ In addition, many studies ${ }^{2,3}$ show that LMP increases considerably with time since onset, whereas Valtonen et al. ${ }^{11}$ found no such association.

In Switzerland, no figures on the LMP of persons with SCI are available to date. The objective of this study was to establish LMP figures of persons with SCI living in Switzerland and to investigate determinants and consequences of having paid work.

\section{MATERIALS AND METHODS \\ Design}

There is no SCI registry in Switzerland to date. Therefore, we conducted a community survey among members of the Swiss Consumer Organization, the Swiss Paraplegic Association (SPA). Community surveys are not subject to ethical approval in Switzerland. The study was approved by the SPA.

\section{Participants}

Members of the SPA with para- or tetraplegia due to an SCI of traumatic or non-traumatic origin, who were older than 18 years at the time of the survey, and were living in the community for at least 1 year.

\section{Data collection and management procedures}

Data were collected online and by postal mail. Participants received an introductory letter, and the survey was announced in the consumer

\footnotetext{
${ }^{1}$ Department of Health Sciences and Health Policy, University of Lucerne and SPF, Nottwil, Switzerland; ${ }^{2}$ Swiss Paraplegic Research (SPF), Nottwil, Switzerland and ${ }^{3}$ Rudolf Magnus Institute of Neuroscience and Center of Excellence in Rehabilitation Medicine, University Medical Centre Utrecht and De Hoogstraat, Utrecht, The Netherlands Correspondence: A Marti, Department of Health Sciences and Health Policy, University of Lucerne, Swiss Paraplegic Research (SPF), Guido A. Zäch Strasse 4, Nottwil CH-6207, Switzerland.

E-mail: albert.marti@paranet.ch

Received 3 May 2011; revised 8 December 2011; accepted 10 December 2011; published online 17 January 2012
} 
magazine 'Paracontact', and on the homepage of the SPA. One reminder letter was sent out and an additional article about the project was published in 'Paracontact' to increase participation in the survey. The survey was performed between May and August 2008.

\section{Measurement}

LMP is understood as paid employment of persons of working age (18-64 years $)^{12}$ in the competitive labour market (LM), including persons who are in paid employment but also have a partial disability pension. Not included are employment in specialised institutions and volunteer/unpaid work.

The self-report 'Nottwil Inventory for the Retrospective Assessment of Labour Market Participation in Spinal Cord Injury' (NIRAL-SCI) was developed in German by the authors to measure the social, health and employment situation of a person with SCI. It included 4 sections, dealing with demographic and injury-related information, social and work related information before and after first rehabilitation, and information about rehabilitation. NIRAL-SCI used multiple-choice questions, five item Likert scales and a visual analogue scale to assess pain. Its development was based on the recommendations of the International Labour Organisation and recent literature on LMP and the determinants of LMP in SCI. ${ }^{3,13,14}$ French and Italian translations were made by a professional translator, and three native speakers checked whether the questions were understandable and feasible. A copy of the questionnaire is available from the corresponding author.

\section{Data analysis}

Data were analysed with SPSS v18. The dependent variable was having paid work versus not having paid work. Group differences were tested using $t$-tests or $\chi^{2}$ tests, and associations were tested using coefficients such as Cramer's V. ${ }^{15}$ Bonferroni correction for multiple testing was applied. Finally, a logistic regression analysis was performed with all selected possible determinants entered at once. Nagelkerke's $R^{2}$ was computed to estimate the percentage of explained variance.

\section{RESULTS}

Of the 2097 persons invited for the study, 559 completed the questionnaire (response rate: 27\%). A total of 495 persons (24\%) met the eligibility criteria. The average time needed to complete the online questionnaire was $41 \mathrm{~min}$. The overall proportion of missing values was small $(2.1 \%)$. The variable 'education within 1 year post SCI' had most missing values (14.6\%).

Socio-demographic and SCI characteristics are displayed in Table 1. A total of 414 persons (83.6\%) of all the participants were of working age at the time of the study. There were no significant differences between participants with paraplegia or tetraplegia, except for a lower participation of paraplegics in vocational training $(44.5 \%$ vs $32 \%$, $P=0.002)$.

\section{LMP figures of study population}

The LMP of the study population at different time points is displayed in Table 2. A total of 483 participants were of working age at the onset of SCI and $87.4 \%$ (381) of them replied that they had ever worked since onset of SCI. The employment rate of persons of working age increased with time after SCI: $36.8 \% 6$ months after initial rehabilitation, $46.2 \% 2$ years after initial rehabilitation, up to $63.8 \%$ at the time of the study (Table 2).

Determinants and consequences of being in gainful employment Bivariate associations of being in gainful employment in 2008 with potential determinants and results of the logistic regression are shown
Table 1 Sociodemographics and SCI-related characteristics

\begin{tabular}{|c|c|c|c|}
\hline Variable & Value & $\begin{array}{c}\text { Percent, } \\
\text { mean/(s.d.) }\end{array}$ & Valid $\mathrm{N}$ \\
\hline \multirow[t]{6}{*}{ Region (location) } & German-speaking & 71.5 & 350 \\
\hline & French-speaking & 20 & 98 \\
\hline & Italian-speaking & 4.5 & 22 \\
\hline & Other & 3.9 & 19 \\
\hline & Total & 100 & 489 \\
\hline & Missing & & 6 \\
\hline Gender & Male & 74.1 & 495 \\
\hline \multirow[t]{2}{*}{ Marital status } & Married & 51.9 & 489 \\
\hline & Missing & & 6 \\
\hline \multirow[t]{2}{*}{ Years of formal education } & & $9.1 /(2)$ & 461 \\
\hline & Missing & & 34 \\
\hline Age in 2008 & & $50.3 /(13.1)$ & 495 \\
\hline Age at onset of $\mathrm{SCl}$ & & $30.9 /(13.3)$ & 495 \\
\hline Time since onset of $\mathrm{SCl}$ (years) & & $18.9 /(11.8)$ & 495 \\
\hline \multirow[t]{2}{*}{ Persons of working age in 2008} & & 83.6 & 414 \\
\hline & Missing & & 81 \\
\hline \multirow[t]{4}{*}{ SCl level } & Tetraplegia & 29.5 & 145 \\
\hline & Paraplegia & 70.5 & 347 \\
\hline & Total & 100 & 492 \\
\hline & Missing & & 3 \\
\hline \multirow[t]{4}{*}{ Impairment } & Complete & 49.5 & 240 \\
\hline & Incomplete & 50.5 & 245 \\
\hline & Total & & 485 \\
\hline & Missing & & 10 \\
\hline \multirow[t]{5}{*}{ Wheelchair dependence } & No & 12.6 & 62 \\
\hline & Electric chair & 6.1 & 29 \\
\hline & Manual chair & 81.3 & 400 \\
\hline & Total & 100 & 491 \\
\hline & Missing & & 4 \\
\hline \multirow[t]{9}{*}{ Main cause of $\mathrm{SCl}$} & Traffic accident & 37.5 & 184 \\
\hline & Fall & 19.8 & 97 \\
\hline & Sport accident & 19.2 & 94 \\
\hline & Disease & 8 & 39 \\
\hline & Operation & 6.1 & 30 \\
\hline & Assault & 1.6 & 8 \\
\hline & Other & 7.8 & 38 \\
\hline & Total & 100 & 490 \\
\hline & Missing & & 5 \\
\hline
\end{tabular}

Abbreviation: SCl, spinal cord injury.

in Table 3. In bivariate analysis, LMP was significantly associated with male gender, receiving vocational counselling, working 2 years after initial rehabilitation, importance of work, pain, and higher formal and professional education. There was no significant association between the level of SCI and having paid work. However, persons with paraplegia worked significantly more hours per week than persons with tetraplegia.

Our logistic regression model explained $47 \%$ of the variance for LMP. Classification was better for working persons ( $90 \%$ correct) than for not working persons (61\% correct). Gender, age, vocational counselling, working 2 years after SCI, time since SCI onset, importance of work, pain, and education were significant determinants of LMP. In contrast to the bi-variate analysis, gender was not a significant predictor in the logistic regression, and age and time since SCI were. Marital status, level of SCI, cause of SCI and having children were not significant determinants in both analyses. 
Table 2 Basic labour market participation figures

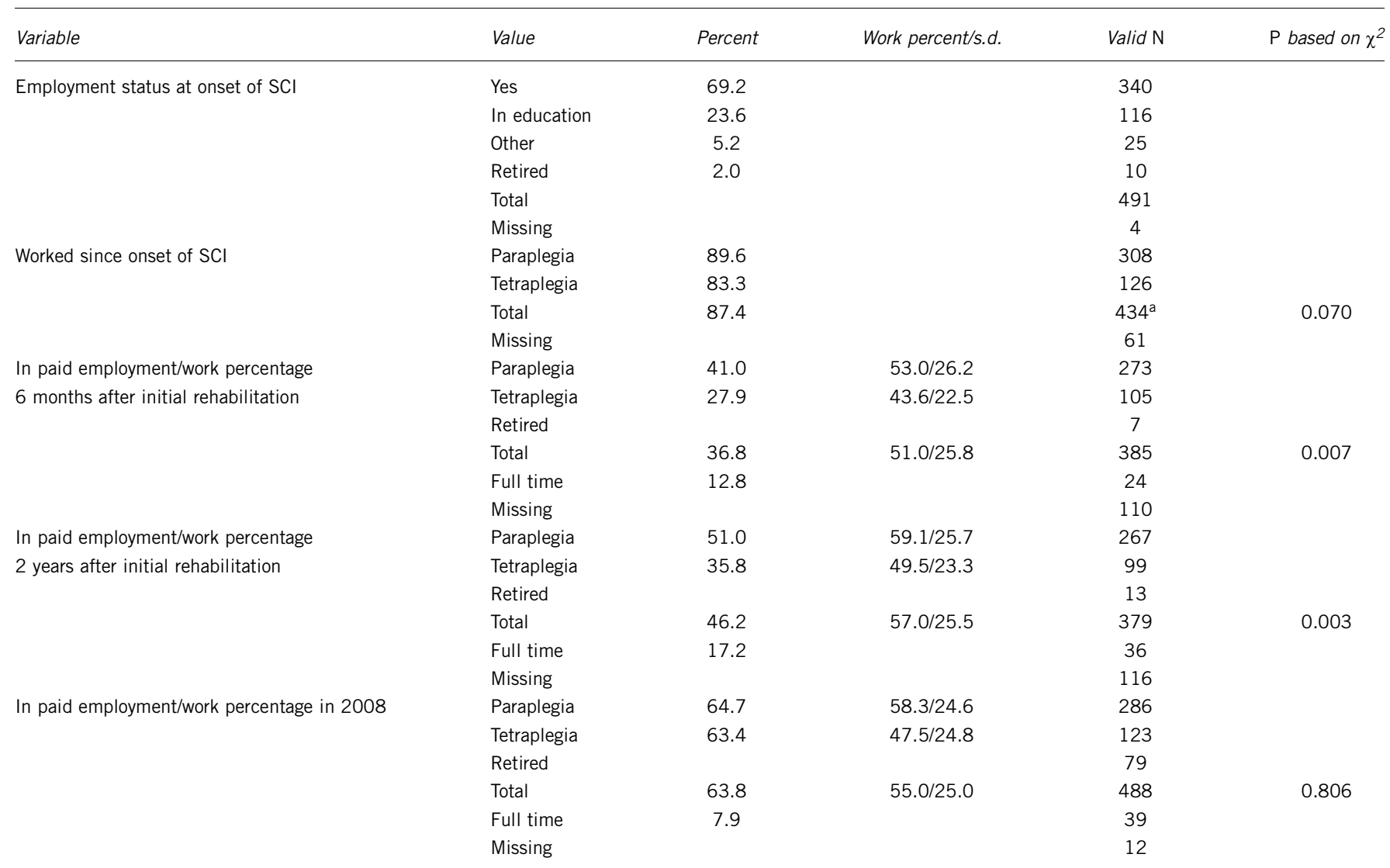

Abbreviation: $\mathrm{SCl}$, spinal cord injury.

apersons in working age at the onset of SCI.

Figure 1 shows LMP by age and time since onset of SCI. Across all age groups LMP of participants with SCI was on average $20 \%$ below that of the general Swiss population. In the group with most recent SCI (injured 1 to 10 years before our survey), there was a significant decrease of the LMP of persons in the 45-54 age group as compared with the other cohorts.

Figure 2 shows the income distribution. Participants who worked had an about $40 \%$ higher total income (pension and earnings) compared with the participants who were not working (mean= $\$ 5582$ and $\$ 3815$ respectively; s.d. $=2755$ and 2644 , respectively; $t=-6.0 ; P<0.001)$.

\section{Reasons for working and perceived barriers to work}

Study participants who worked were asked for their motives to work. The most frequent answer was that working brought satisfaction (84.6\%), followed by establishing contacts with others $(71.4 \%)$ and the need for money $(70.3 \%)$. Less frequent $(<40 \%)$ answers were: 'I feel bored otherwise' (37.2\%), 'work distracts me from physical problems' (36.5\%), 'I feel obliged to society' (32.3\%), 'work distracts me from mental problems' (22.6\%), and 'my environment expects me to work' $(16.5 \%)$.

The participants of working age who were not working at the time of the survey were asked why they did not work. The most important answer was: 'I have too many health problems', followed by 'too much pain' and that 'it was not possible to find a suitable job'. (Figure 3).

\section{DISCUSSION}

Our study showed a relatively high participation rate $(63.8 \%)$ among the studied persons with SCI in the Swiss labour market, ${ }^{5}$ compared with other European countries, that showed a much lower average LMP of $36 \%$ (s.d.=14.6). ${ }^{3}$ Comparisons with other studies are however limited because our study population had a higher mean age and included fewer persons with tetraplegia than most other studies. ${ }^{5}$ We found that the LMP in persons with SCI is similar to the LMP (64\%) of all persons with disabilities in Switzerland. ${ }^{16}$ In an international perspective, both the LMP of all persons with disabilities (64\% vs $50 \%$ in the $27 \mathrm{EU}$ countries) and the LMP of the general population $(79.5 \%$ in Switzerland vs $65.9 \%$ in the 27 EU countries) is relatively high in Switzerland. ${ }^{12,17}$ The difference between Switzerland and Europe in LMP of persons with SCI (28\%) is, however, double the difference in LMP of all persons with disabilities $(14 \%)$. Further research is necessary to explore this difference.

Findings in the literature concerning gender are inconsistent. ${ }^{2,18}$ In our study, gender marginally missed significance in the logistic regression analysis. The literature in SCI shows a trend that men are more likely to work than women, which was also found in our bivariate analysis. $^{2}$ The LMP of women in our study is more than $30 \%$ lower than that of comparable women of the general population. ${ }^{12}$ It may be suggested that taking care of children is more time consuming and more difficult to combine with gainful employment for women with SCI than for women in the general population. However, 
Table 3 Determinants of labour market participation

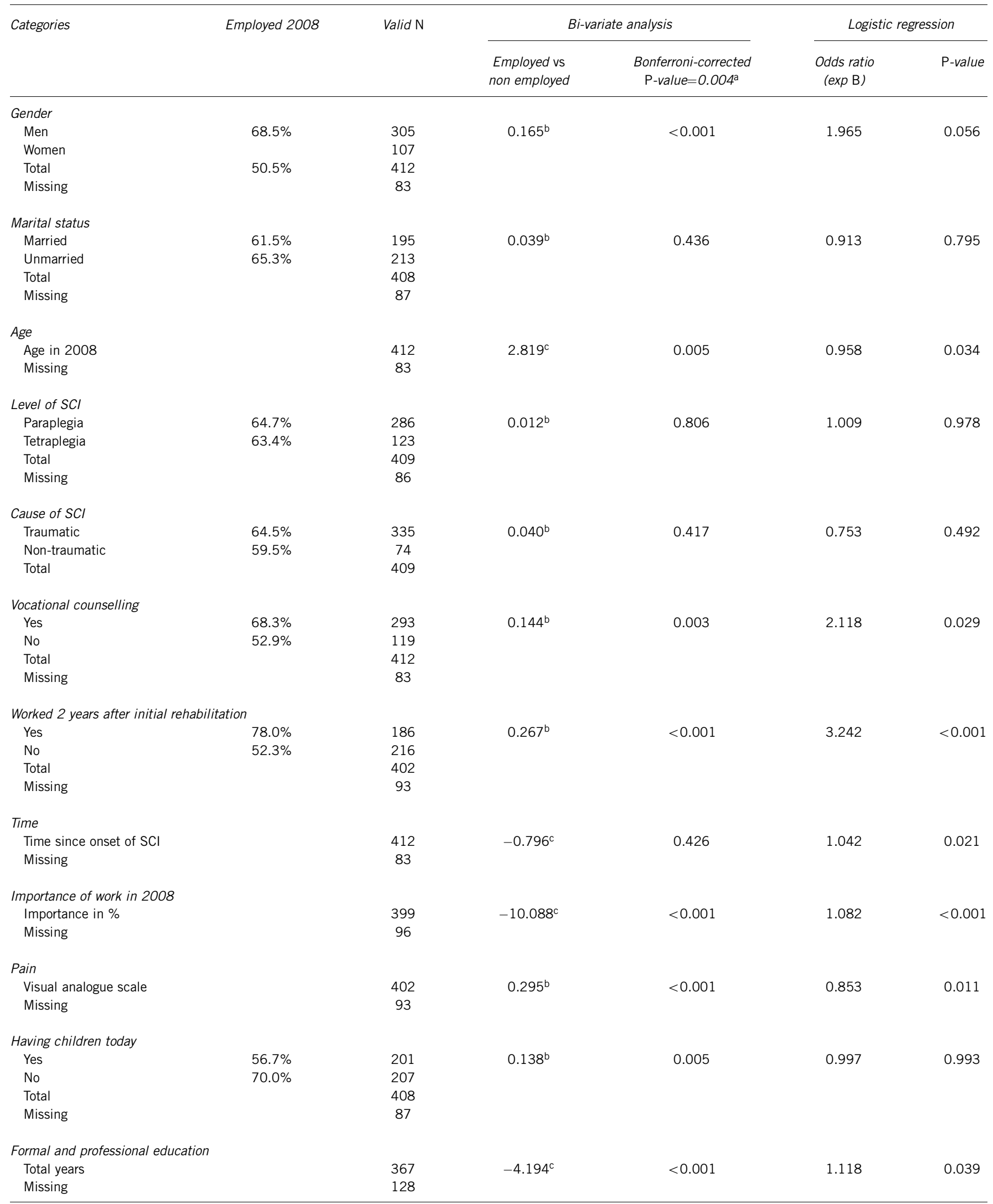

Abbreviation: $\mathrm{SCl}$, spinal cord injury.

a 0.05 divided by 12 .

${ }^{b}$ Cramer's $V\left(P\right.$-value based on $\left.\chi^{2}\right)$.

${ }^{c} t$-value independent samples. 

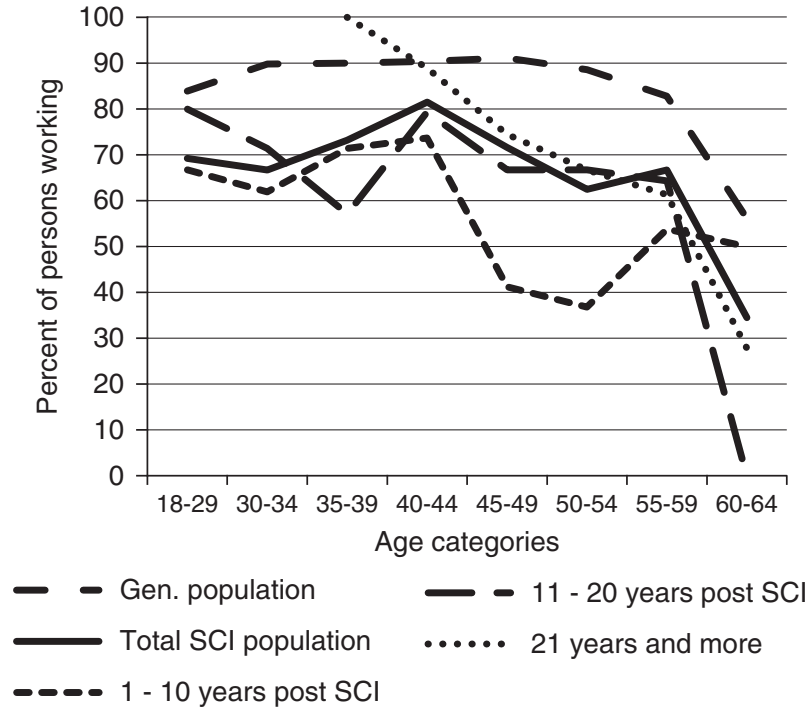

Figure $1 \mathrm{LMP}$ in relation to age and time since injury $(N=412)$.

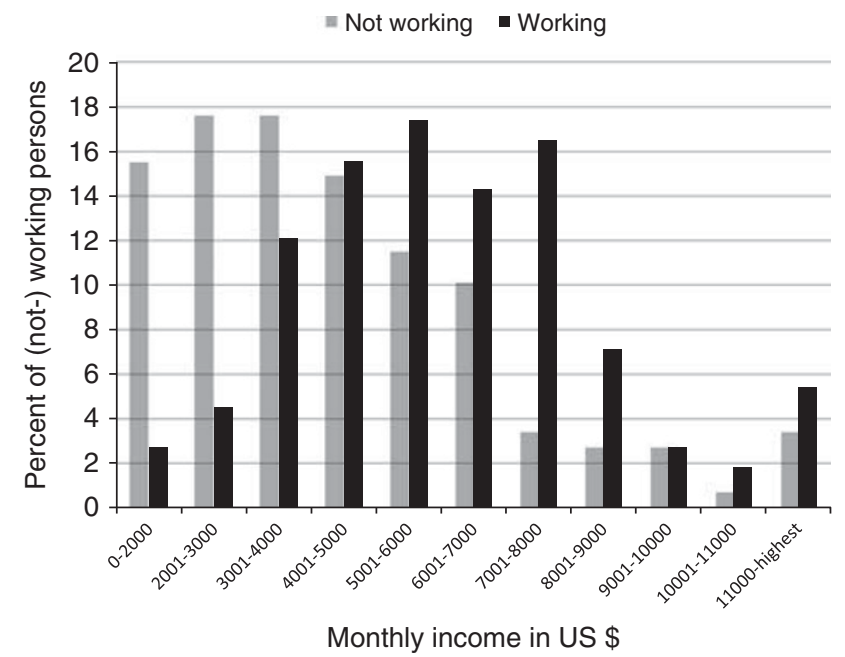

Figure 2 Monthly income and work status ( $N=372)$. having children alone was not a significant predictor of LMP. Future research may consider respective interaction terms.

Age and time since onset of SCI were related to LMP in the logistic regression analysis. Age would have been significant also in the bi-variate analyses if these would have been performed without correction for multiple testing. Most other studies found employment to increase with time. ${ }^{2-3,5}$ We found that LMP increases up to 15 years after SCI onset, but plateaus at around 40 with more than $80 \%$ of persons with SCI working, and this percentage falls afterwards. ${ }^{8,19}$ Rather surprising is the low LMP of persons between 45 and 54, and who sustained their SCI 1 to 10 years before this study. (Figure 1). One reason may be that lax policy on disability benefits has resulted in a generally high rate of new disability pension recipients in the 1990s and in the beginning of the 2000s. ${ }^{20-21}$

As in many other studies, our results show an association between pain and LMP. ${ }^{3}$ Another finding was the weak but significant association between received vocational counselling and better LMP. The same finding was reported by Schönherr et al. ${ }^{22}$ for the Netherlands.

According to Krause, ${ }^{20}$ a fast track exists where people return to their pre-injury job, and a slower track that is associated with re-education and training. Our study results support this finding. As mentioned before, rates increase up to 15 years post injury. Our analysis also showed that having work 2 years after initial rehabilitation is the most important predictor for later LMP.

Another finding was, that persons who rated the importance of work higher compared with other life areas (family, friends, leisure, sport), had a significantly better LMP. Anderson et al. ${ }^{2}$ also stated that the value placed on work and level of motivation are among the most important predictors for LMP. Our impression is that it might be important to pay more attention to work motivation during rehabilitation.

As in many other studies education had a significant influence on LMP. $^{5}$ The same holds true for the employment situation before onset of SCI. Persons who were unemployed, received a disability pension or cared for the household were less often employed, which is also consistent with the literature. ${ }^{19}$

Looking at the non-significant determinants in our study, the most striking result is that level of SCI had no influence on LMP. Anderson et al. ${ }^{2}$ reported that findings on severity of injury are inconsistent and other studies found no influence as well. Unlike other studies, we

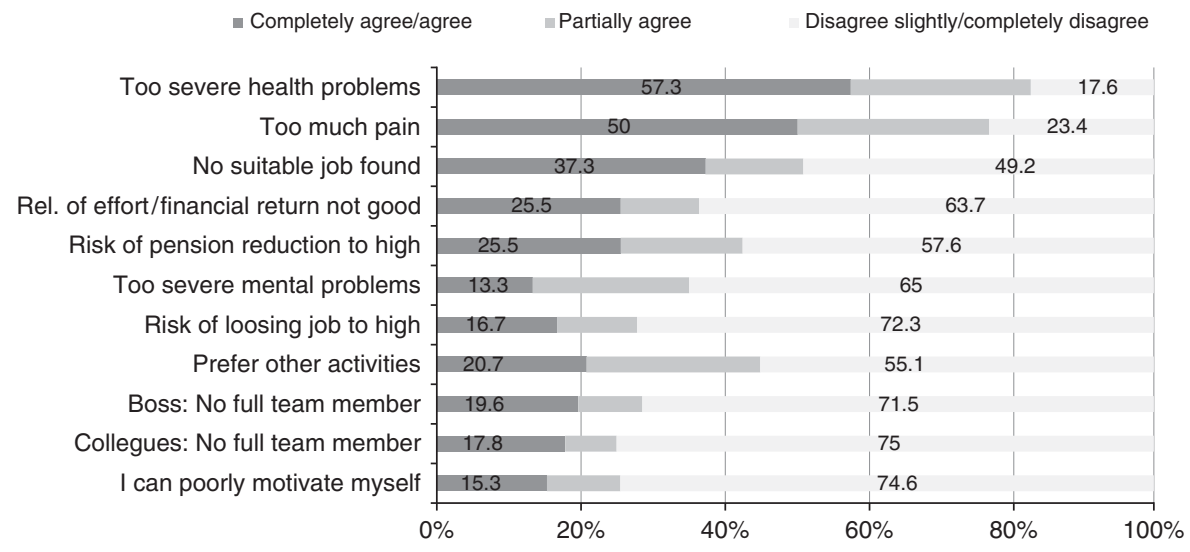

Figure 3 Perceived barriers to work $(N=239)$. 
also found no influence of traumatic vs non-traumatic cause of SCI. It has been suggested that LMP after an SCI is related to receiving a compensation, which in some countries is only paid after traumatic SCI, for example, a car accident. ${ }^{2}$ However, in Switzerland compensation is largely dependent on work status at SCI onset and not on cause of SCI.

We found that the differences in income between persons with and without work are in line with the findings for the whole population with disability in the OECD (Organisation for Economic Co-operation and Development) countries. ${ }^{1}$ One reason might be the generally higher compensation for inflation by employers than by the disability insurance, so that the real income of persons with SCI decreases over the years. ${ }^{23}$

The two barriers perceived as most important for not being employed, having too much health problems or too much pain, were health related and are also reflected in the literature. ${ }^{18}$ The next most frequent answer was not being able to find a suitable job, which was also found by Ottomanelli et al. ${ }^{5}$

\section{Limitations of the study}

Limitations of the study include the low response rate of about $24 \%$, which limits the generalisation (that is, external validity) and the study results have to be interpreted with caution. Further, we only surveyed members of the SPA, and we did not have the possibility to collect information on non-responders. The proportion of respondents with tetraplegia was relatively low, wherein we found a high rate of working persons with tetraplegia. Therefore, we cannot exclude that working persons with tetraplegia participated disproportionately. Although the multivariate analysis did not show a significant influence of cause of SCI we cannot exclude that this is an artifact due to self-selection of specific non-traumatic cases. Data on conditions that caused nontraumatic SCI are not available for our study. We cannot exclude that persons with a more problematic LMP responded less often than more successful persons.

\section{CONCLUSION}

Our study provides first data on LMP after SCI in Switzerland. We found a relatively high rate of persons with SCI who are working. Owing to the low return quote, it is, however, difficult to generalise this finding.

\section{CONFLICT OF INTEREST}

The authors declare no conflict of interest.
1 Organisation for Economic Co-operation and Development. Transforming Disability into Ability: Policies to Promote Work and Income Security for Disabled People. Organisation for Economic Co-operation and Development: Paris, France, 2003.

2 Anderson D, Dumont S, Azzaria L, Le Bourdais M, Noreau L. Determinants of return to work among spinal cord injury patients: a literature review. J Vocational Rehabil 2007; 27: 57-68.

3 Lidal IB, Huynh TK, Biering-Sørensen F. Return to work following spinal cord injury: a review. Disabil Rehabil 2007; 29: 1341-1375.

4 Lengnick-Hall ML, Gaunt PM, Kulkarni M. Overlooked and underutilized: people with disabilities are an untapped human resource. Hum Resour Manage 2008; 47: 255-273.

5 Ottomanelli L, Lind L. Review of critical factors related to employment after spinal cord injury: implications for research and vocational services. J Spinal Cord Med 2009; 32: 503-531.

6 Jang $\mathrm{Y}$, Wang Y-H, Wang J-D. Return to work after spinal cord injury in Taiwan: the contribution of functional independence. Arch Phys Med Rehabil 2005; 86: 681-686.

7 Krause JS. Aging and self-reported barriers to employment after spinal cord injury. Top Spinal Cord Injury Rehabil 2001; 6: 102-115.

8 Krause JS, Coker JL. Aging after spinal cord injury: a 30-year longitudinal study. J Spinal Cord Med 2006; 29: 371-376.

9 Krause JS, Reed KS. Barriers and facilitators to employment after spinal cord injury: underlying dimensions and their relationship to labor force participation. Spinal Cord 2011; 49: 285-291.

10 Kurtaran A, Akbal A, Ersoz M, Selcuk B, Yalcin E, Akyuz M. Occupation in spinal cord injury patients in Turkey. Spinal Cord 2009; 47: 709-712.

11 Valtonen K, Karlsson AK, Alaranta H, Viikari-Juntura E. Work participation among persons with traumatic spinal cord injury and meningomyelocele1. J Rehabil Med 2006; 38: 192-200.

12 BfS. Erwerbstätigenquoten nach Nationalität, Altersgruppe und Familientyp 19912010 Available from: http://www.bfs.admin.ch/bfs/portal/de/index/themen/03/02/ blank/data/03.html (accessed 17 March 2011).

13 Siegrist J, Starke D, Chandola T, Godin I, Marmot M, Niedhammer I et al. The measurement of effort-reward imbalance at work: European comparisons. Soc Sci Med 2004; 58: 1483-1499.

14 International Labour Organization. The Employment Situation of People with Disabilities: Towards Improved Statistical Information, 1st edn. International Labour Office: Geneva, 2007.

15 Chen PY, Popovich PM. Correlation r: Parametric and Nonparametric Measures. Sage Publications: Thousands Oaks, CA, 2002.

16 BfS. Gleichstellung von Menschen mit Behinderungen 2007. Available from: http:// www.bfs.admin.ch/bfs/portal/de/index/themen/20/06/blank/key/00.html (accessed 17 March 2011).

17 Eurostat. Erwerbstätigenquote nach Geschlecht 2011 Available from: http://epp. eurostat.ec.europa.eu/tgm/table.do?tab=table\&language $=$ de \&pcode $=$ tsiem00\&table Selection=1\&footnotes=yes\&labeling=labels\&plugin $=1$ (accessed 31 March 2011).

18 Yasuda S, Wehman P, Targett P, Cifu DX, West M. Return to work after spinal cord injury: a review of recent research. Neurorehabilitation 2002; 17: 177-186.

19 Pflaum C, McCollister G, Strauss DJ, Shavelle RM, DeVivo MJ. Worklife after traumatic spinal cord injury. J Spinal Cord Med 2006; 29: 377-386.

20 Krause JS. Years to employment after spinal cord injury. Arch Phys Med Rehabil 2003; 84: 1282-1289.

21 Krause JS, Terza JV, Saunders LL, Dismuke CE. Delayed entry into employment after spinal cord injury: factors related to time to first job. Spinal Cord 2010; 48: 487-491.

22 Schönherr MC, Groothoff JW, Mulder GA, Schoppen T, Eisma WH. Vocational reintegration following spinal cord injury: expectations, participation and interventions. Spinal Cord 2004; 42: 177-184.

23 Berkowitz M. Spinal Cord Injury: An Analysis of Medical and Social Costs. Demos: New York, NY, 1998. 